\title{
Histological and Histochemical Characterization of the Midgut of Healthy Aedes aegypti Larvae
}

\author{
A. B. de Lemos ${ }^{1 *}$, F. C. Adam ${ }^{1}$, K. R. S. de Moura ${ }^{2}$, L. B. de Moraes ${ }^{3}$ \\ and O. S. da Silva ${ }^{1}$ \\ ${ }^{1}$ UFRGS - Universidade Federal do Rio Grande do Sul, Rua Sarmento Leite, 500 - Bairro Farroupilha, \\ CEP 90050-170, Porto Alegre/RS, Brazil. \\ ${ }^{2}$ UFSC - Universidade Federal de Santa Catarina, Rua Eng. Agronômico Andrei Cristian Ferreira, \\ $s / n$ - Bairro Trindade, CEP 88040-900, Florianópolis/SC, Brazil. \\ ${ }^{3} I P V D F$ - Instituto de Pesquisas Veterinárias Desidério Finamor, Estrada Do Conde, 6000 - Bairro \\ Sans Souci, CEP 92990-000, Eldorado do Sul/RS, Brazil.
}

\section{Authors' contributions}

This work was carried out in collaboration between all authors. Author ABL was responsible for developing all steps of this work and wrote the first draft of the manuscript. Author FCA helped with the histological methodology. Author KRSM was responsible for helping in histological and histochemical characterization. Author LBM offered his laboratory for cutting the histological material and author OSS was responsible for supervising the research. All authors read and approved the final

manuscript.

Article Information

DOI: $10.9734 / A R R B / 2018 / 37443$

Editor(s):

(1) George Perry, Dean and Professor of Biology, University of Texas at San Antonio, USA.

Reviewers:

(1) Eyyüp Mennan Yildirim, Adnan Menderes University, Turkey.

(2) Bela Nabar, Mumbai University, India.

(3) Nayana Gunathilaka, University of Kelaniya, Sri Lanka Complete Peer review History: http://www.sciencedomain.org/review-history/22646

Original Research Article

Received $16^{\text {th }}$ October 2017

Accepted $5^{\text {th }}$ December 2017 Published $9^{\text {th }}$ January 2018

\begin{abstract}
Aedes aegypti (Diptera, Culicidae) is the predominant mosquito vector of several arboviruses such as dengue fever, yellow fever, chikungunya and zika. The larval stage is the major period of feeding and growth of these insects. Many of the products tested for Ae. aegypti control are ingested by the larvae in their natural environment or under laboratory conditions. In some situations, the identification of tissue lesions caused by the ingestion of such products serves as the primary way to understand their mechanism of action and confirm their effectiveness.
\end{abstract}


Therefore, we aimed to conduct studies on the histological and histochemical characteristics of $A e$. aegypti larvae in order to contribute to a better understanding of the pathogenicity caused by chemical or biological products for larval control. Therefore, we characterized tissues in the midgut of healthy $A e$. aegypti larvae and present high quality images. These images are intended for comparison with results of morphohistochemical studies testing the effect of control substances in mosquito larvae.

Keywords: Aedes aegypti; midgut; histology; histochemistry.

\section{INTRODUCTION}

Aedes aegypti (Diptera, Culicidae) is the main mosquito vector of several arboviruses such as dengue fever, chikungunya and zika. This mosquito species is widely distributed in tropical and subtropical areas of the world [1]. In Brazil Ae. aegypti can be find in all regions of this country [2].

According to [3] of all arboviruses, dengue is the most prevalent human arboviral infection. The actual numbers of dengue cases are underreported, and many cases are misclassified. However, annually approximately 390 million people become infected with this arbovirus.

The better way for controlling Ae. aegypti is through their larvae. Such control must be combined using chemical and biological targeting of Aedes mosquitoes and management of breeding sites [4]. However, depending on the area of distribution many Ae. aegypti populations have become resistant to chemical insecticides [5], as well as biological insecticides [6,7].

In response to the growing number of resistant Ae. aegypti populations, several studies have attempted to identify substances derived from other synthetic chemicals, products isolated from plants $[8,9]$ and microorganisms, which may serve as alternative control methods [10-12].

The larval stage is the major period of feeding and growth of these insects. Therefore, many of the products tested for their control are administered to the larvae in their natural environment or under laboratory conditions. According to [13], the midgut is highly representative of the interconnection between the larvae and their environment. The understanding its morphology and physiology is essential for assessing such control methods.
In some situations, the identification of tissue lesions caused by products aimed at control is fundamental for understanding the mechanism of action of these products and confirming their effectiveness in insects. These analyses are usually based upon morphological and pathogenic tissue differences between insects exposed to chemical compounds or biological products and those with healthy tissues [14-20].

As mentioned above, these studies highlight the importance of knowing the mode of action and the target site of larvicides. However, despite several papers citing histological changes, there is a lack of histological and histochemical descriptions of healthy mosquito larvae. This makes it difficult for researchers that need to make comparisons between injured and healthy tissues to confirm their findings. Thus, the extent of comparison becomes impaired, which hinders the description of these tissues.

In these studies, most findings are identified and described based on optical microscopy images. However, factors such as low image quality, lack of information about the exact location evaluated and the absence of sequential histological sections can result in insufficient data for precise evaluation. In addition, there is a lack of descriptions related to healthy mosquito tissues, variations among healthy tissues and normal physiological activities, among others, which could help researchers investigating substances for mosquito control. Therefore, we aimed to present studies on the histology and histochemistry of $A e$. aegypti larvae to contribute to a better understanding of pathogenicity caused by chemical or biological products for larval control. To achieve this, we characterized healthy tissues of the digestive tract of $A e$. aegypti larvae, specifically the midgut, presenting high-quality images and providing a basis for more comprehensive comparison in morphological studies of mosquito larvae. 


\section{MATERIALS AND METHODS}

\subsection{Maintenance of Ae. aegypti Colony}

In this study a colony of the Rockefeller strain, established in the Sector of Parasitology at the Federal University of Rio Grande do Sul, was used.

\subsection{Preparation of the Material}

Twenty larvae (late third or early fourth instars) were placed still alive in Bouin's solution for 24 hours at room temperature. After this period, they were washed with $70 \%$ alcohol in order to eliminate any residue.

Dehydration was performed by immersing larvae in a series of increasing ethanol concentrations, beginning with $70 \%$ for 10 minutes, $95 \%$ for 15 minutes, absolute ethanol for 20 minutes, then again for 30 minutes.

The larvae were embedded in resin solution (Leica Historesin Embedding Kit) at room temperature. The embedding was made in polyethylene molds ( $6 \times 8 \mathrm{~mm}$; Leica), and each block contained two larvae positioned lengthwise. The molds were kept at $40^{\circ} \mathrm{C}$ for at least 12 hours for ensure complete polymerization of the resin.

Longitudinal sections $(3 \mu \mathrm{m})$ were cut using a semi-automatic rotary microtome (Precision YD335 - Button Panel) with disposable blades (Histoblade). For each block of resin, 10 to 15 microscopy slides were prepared, on which six sequential sections were fixed. These slides were stored in a drying oven at $30 \pm 2{ }^{\circ} \mathrm{C}$ for at least 24 hours. Finally, the sections were stained with Harris' hematoxylin and eosin for the histology analysis. For histochemical characterization, bromophenol blue, Nile blue, toluidine blue and Periodic acid Schiff (PAS) stains were used.

The material was examined and photographed using an Olympus microscope (BX41). The scale bar was determined using ImageJ software version $1.50 f$.

\section{RESULTS AND DISCUSSION}

\subsection{Morphological Aspects}

The body of the larva consists of a head, thorax and 10 externally visible abdominal segments.
Internally, the digestive system is divided into three parts (stomodeum or foregut, mesenteron or midgut, and proctodeum or hindgut). The mesenteron has to be distinctly observed in the anterior, middle and posterior regions. This division only serves to facilitate the histological description, as there are notable morphological differences between these regions. The anterior region of the mesenteron begins with the gastric caeca in the first abdominal segment, the middle region is located between segments II and III, and the posterior segment is equivalent to segments IV and V. The other segments belong to the hindgut (Fig. 1).

Some aspects must be observed. The use of distilled water is fundamental to obtain the best visualization of the structures. This is because the historesin remains in the sampled material which is then stained, including the dirt materials.

The morphological aspects of the digestive system must be analyzed in sequential slides. It's because is rare to see all materials on the same microscopy slide due to some larval torsion occurred during the inclusion process. Even so, it is possible to facilitate analysis of nearby structures, such as observation of the foregut. In this region, the proventriculus can be easily observed (Fig. 2).

Regarding the foregut, the best observed structure is the proventriculus, which presents as an invagination of the esophagus surrounded by a layer of columnar epithelium, similar to the cells of the midgut. According to [21], these cells are responsible for secreting the peritrophic membrane, while the remaining structures will ultimately shape this structure by compression. This region is important as it actively participates in mechanical defense processes against pathogens that may have been ingested by the larvae.

Even when the sections are superficial it is possible to observe three gastric caeca, two lateral and one central (Fig. 3). The remaining structures of the foregut and midgut are not apparent. Only the lateral caeca are evident in deeper sections, and among them, one can see the remaining structures. The gastric caeca cells are large, slightly flattened, with clear edges along the brush border, which contrasts with the description by [18] who suggested that these cells did not have well-developed microvilli (Fig. 4). 


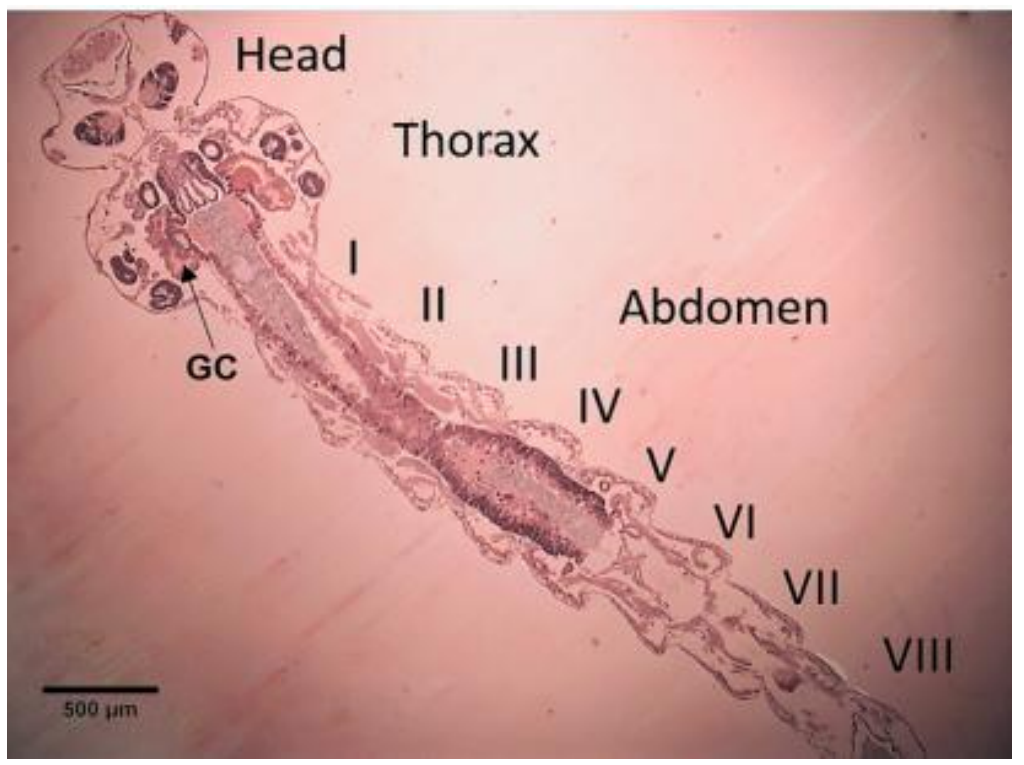

Fig. 1. Abdominal segments of Aedes aegypti larvae. The anterior region of the mesenteron is composed of the gastric caeca (GC) in segment $I$. The middle region of the mesenteron is present in segments II and III, and the posterior region of the mesenteron is in segments IV and V. Segments VI to VIII are below in the proctodeum. Stained with H\&E, image taken at 40X magnification

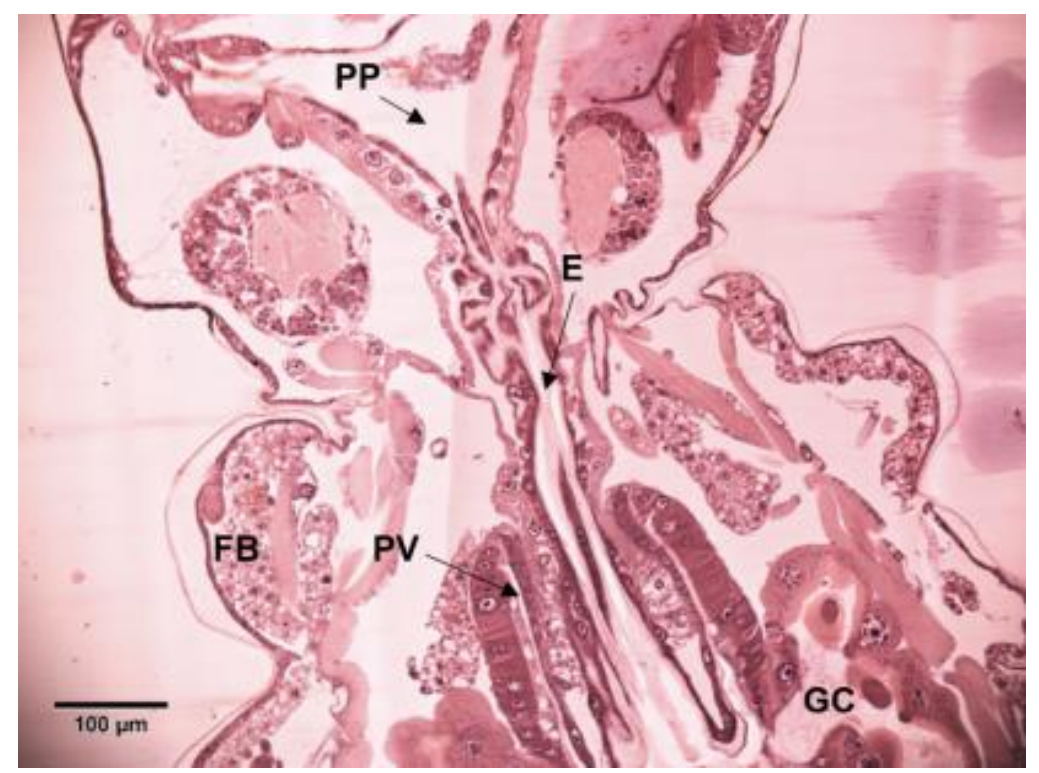

Fig. 2. General overview of the anterior part of Aedes aegypti larvae showing part of the head and thorax. Stained with H\&E, image taken at 200X magnification. E, esophagus; FB, fat body; GC, gastric caeca; PP, pharyngeal pump; PV, proventriculus

The brush border consists of microvilli which assist in the absorption of nutrients, and these structures are acidophilic when stained by eosin. However, epithelial cells of the midgut also play a role in the secretion of substances. The epithelium is composed of a rectangular, uniform, single layer of cubical and cylindrical cells, highlighting the brush border. Regenerative cells appear at the base of the tissue where they are interleaved between epithelial cells, and are 
generally easily visualized (Fig. 5). The nuclei are central and globular, and the cytoplasm can range from smooth and heterogeneous to granular with basophilic regions (Fig. 6).

We observed a slight variation in cytoplasm color. Underneath the villi the staining is more basophilic, which becomes more acidophilic toward the center of the cell. This variation shows intense metabolic activity. The nucleolus appears well-defined, and the nucleus is always granular. In some cells the granular pattern appears to be more peripheral.

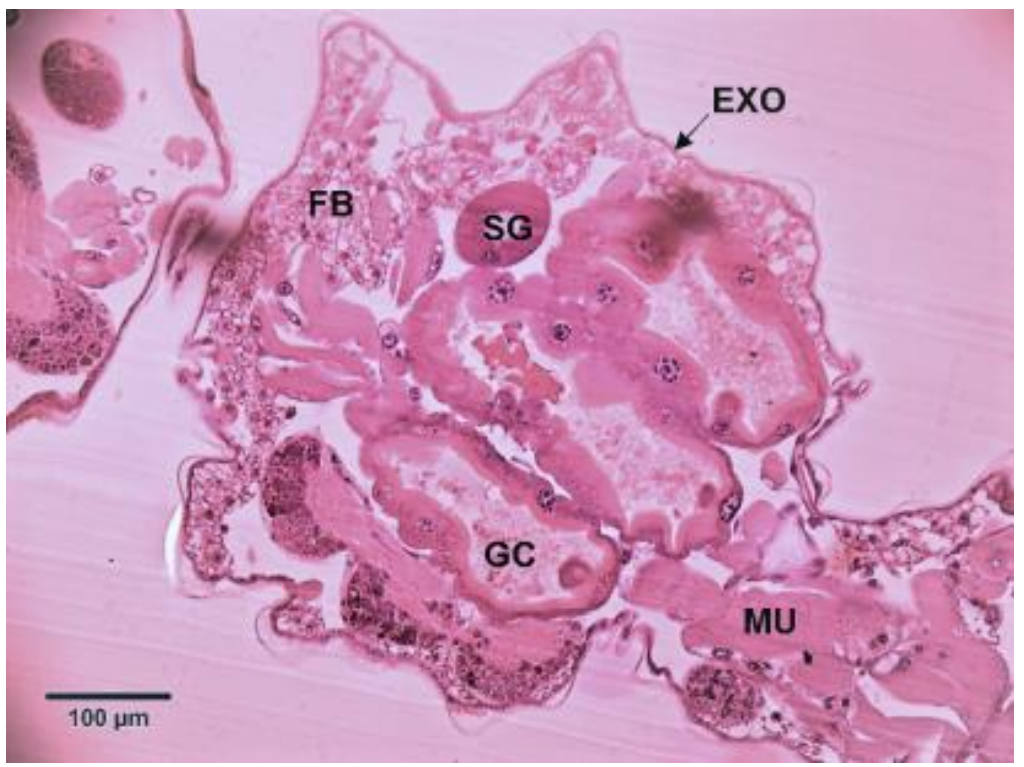

Fig. 3. Superficial section containing three gastric caeca. Stained with H\&E, image taken at 200X magnification. EXO, exoskeleton; FB, fat body; GC, gastric caeca; MU, muscle; SG, salivary gland

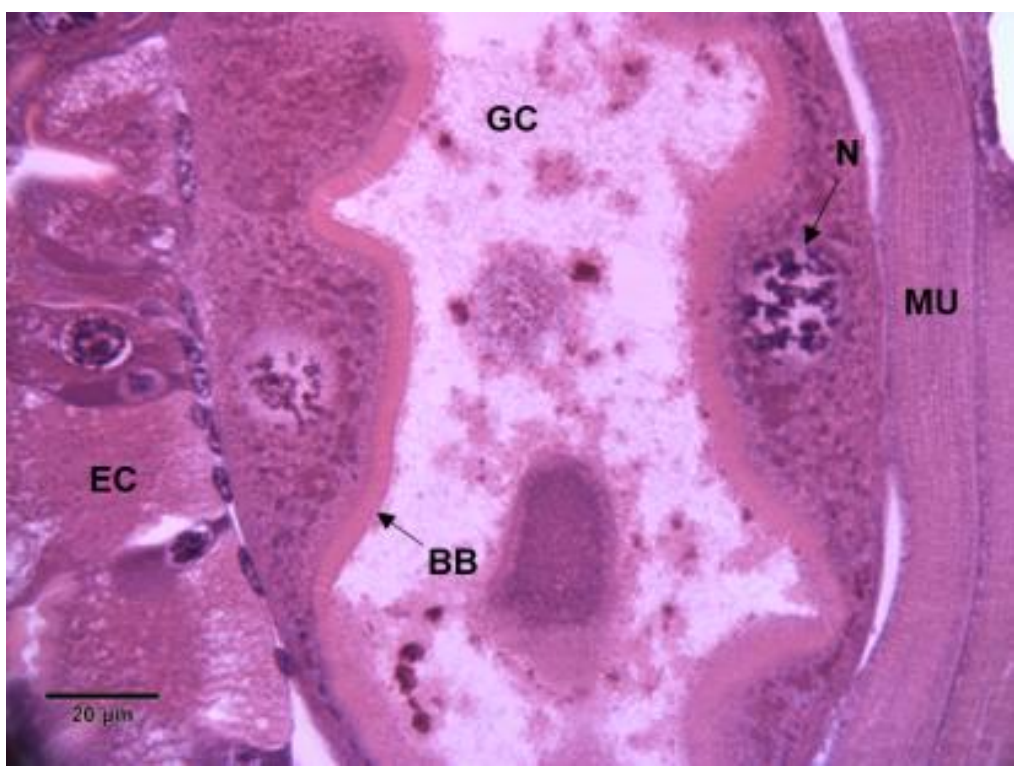

Fig. 4. Epithelial cells of the gastric cecum showing the brush border. Stained with H\&E. Image taken at 1000X magnification. BB, brush border; EC, epithelial cell; GC, gastric caeca; MU, muscle; $\mathrm{N}$, nucleus 


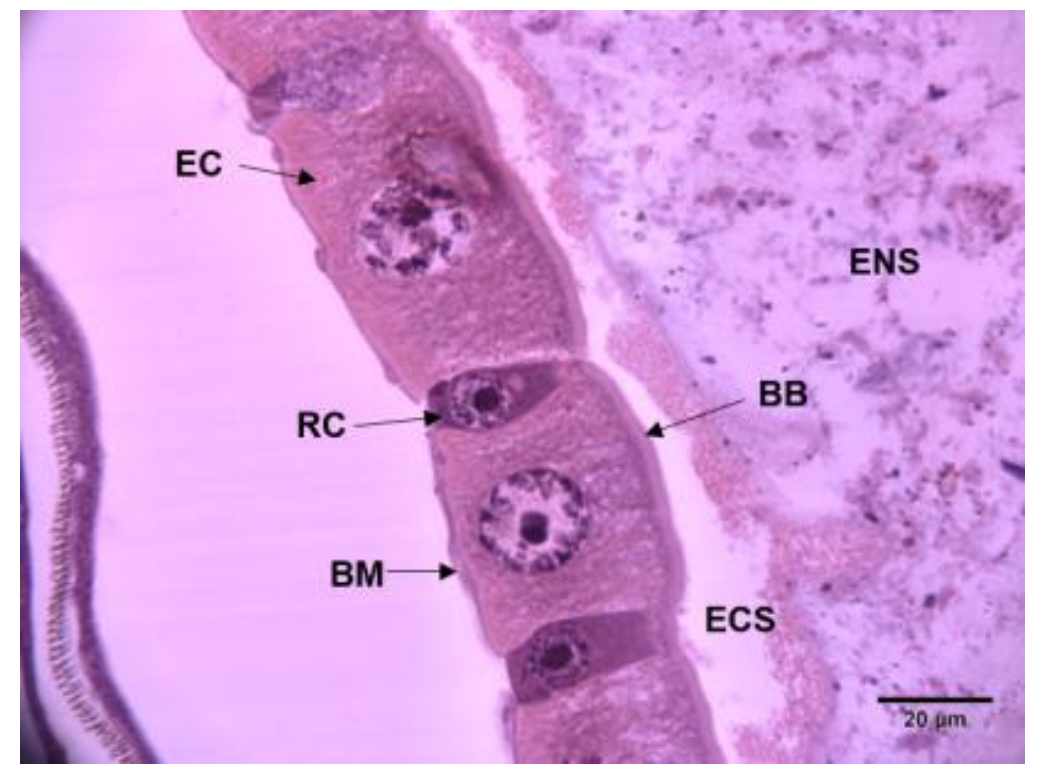

Fig. 5. Section showing a single layer of epithelial cubic cells in the mesenteron with intercalated regenerative cells. Stained with H\&E, image taken at $1000 \mathrm{X}$ magnification. BB, brush border; BM, basal membrane; EC, epithelial cell; ECS, ectoperitrophic space; ENS, endoperitrophic space; RC, regenerative cell

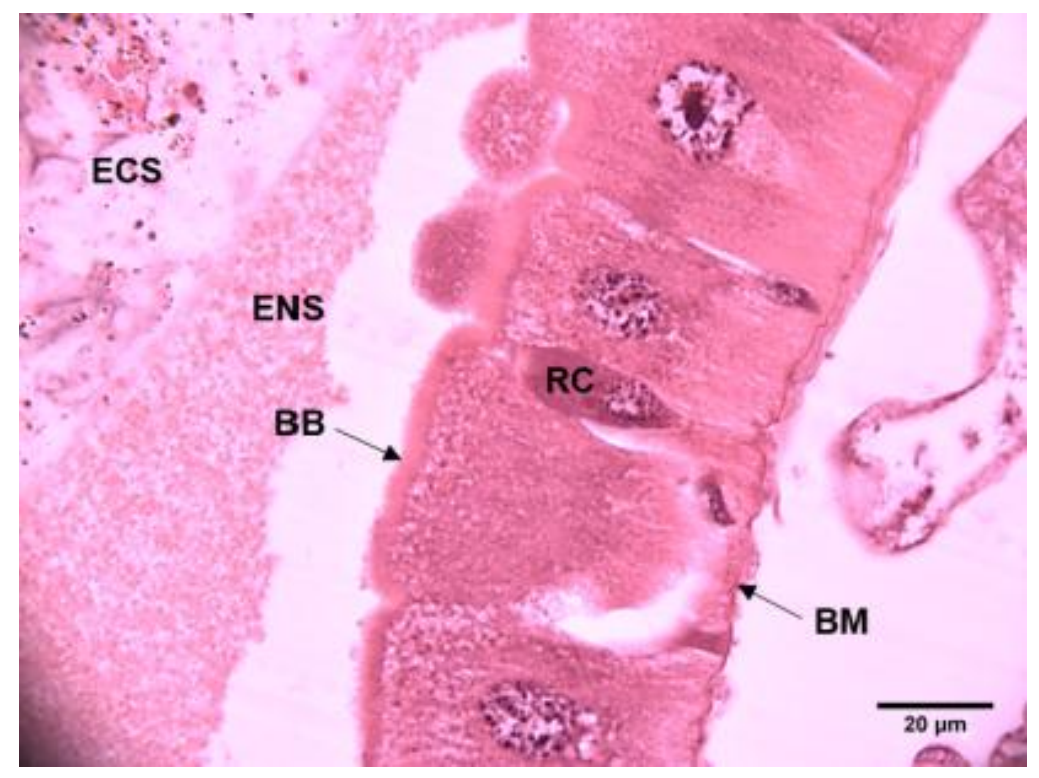

Fig. 6. Section of epithelial tissue of mesenteron showing cubic and columnar cells with a central nucleus and a smooth and heterogeneous cytoplasm. Stained with H\&E, image taken at $1000 \mathrm{X}$ magnification. BB, brush border; BM, basal membrane; ECS, ectoperitrophic space; ENS, endoperitrophic space; RC, regenerative cell

Some larvae presented a higher number of regenerating cells and fewer regular cells in all regions of the midgut, often combined with a higher quantity of vesicles in the lumen, making it appear full of cellular material (Figs. 7 and 8).
Secretory activity is common in the posterior region of the mesenteron; however, this activity was also high in the anterior and middle regions in two samples. This pattern may be related the proximity of ecdysis. This is supported by $[21,22]$, 
who both described that the morphological tissue differs according to the age of the larvae. The larvae that were closest to pupation had less homogeneous epithelial tissue. It is well-known that secretory actions may cause cell injury, therefore, this should be carefully observed.

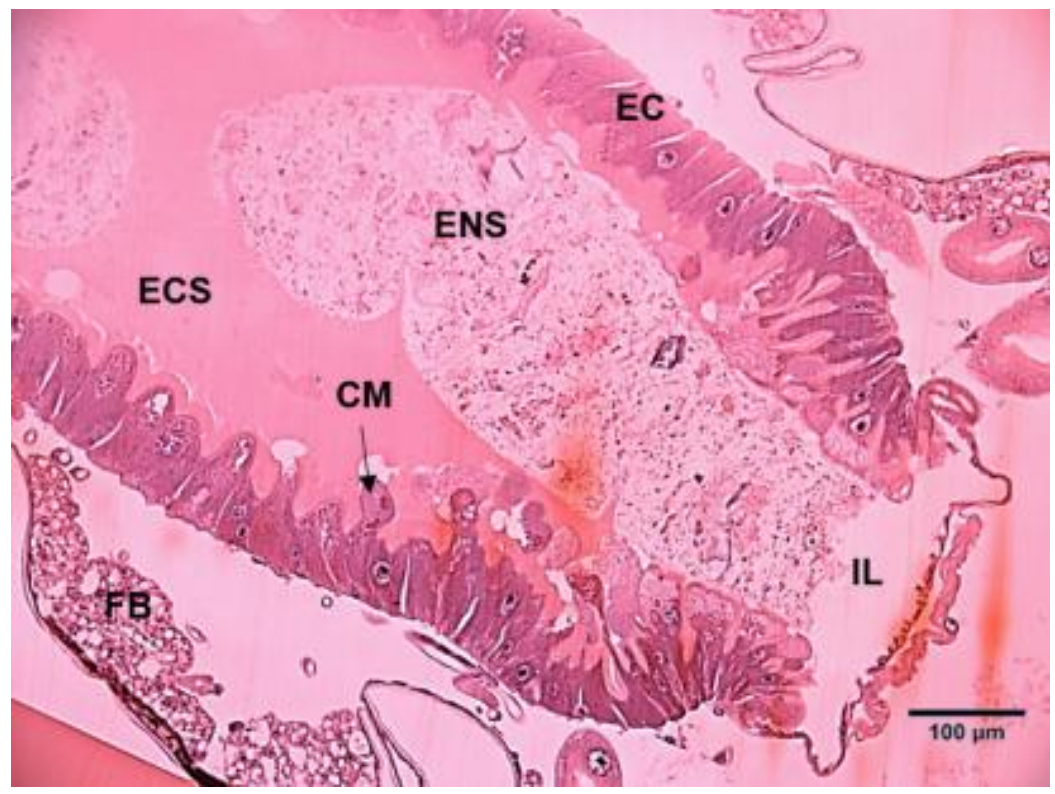

Fig. 7. Epithelial tissue with high secretory activity in which the tissue appears to be less standardized. Stained with H\&E, image taken at 200X magnification. CM, cellular material; EC, epithelial cell; ECS, ectoperitrophic space; ENS, endoperitrophic space; FB, fat body; IL, ileum

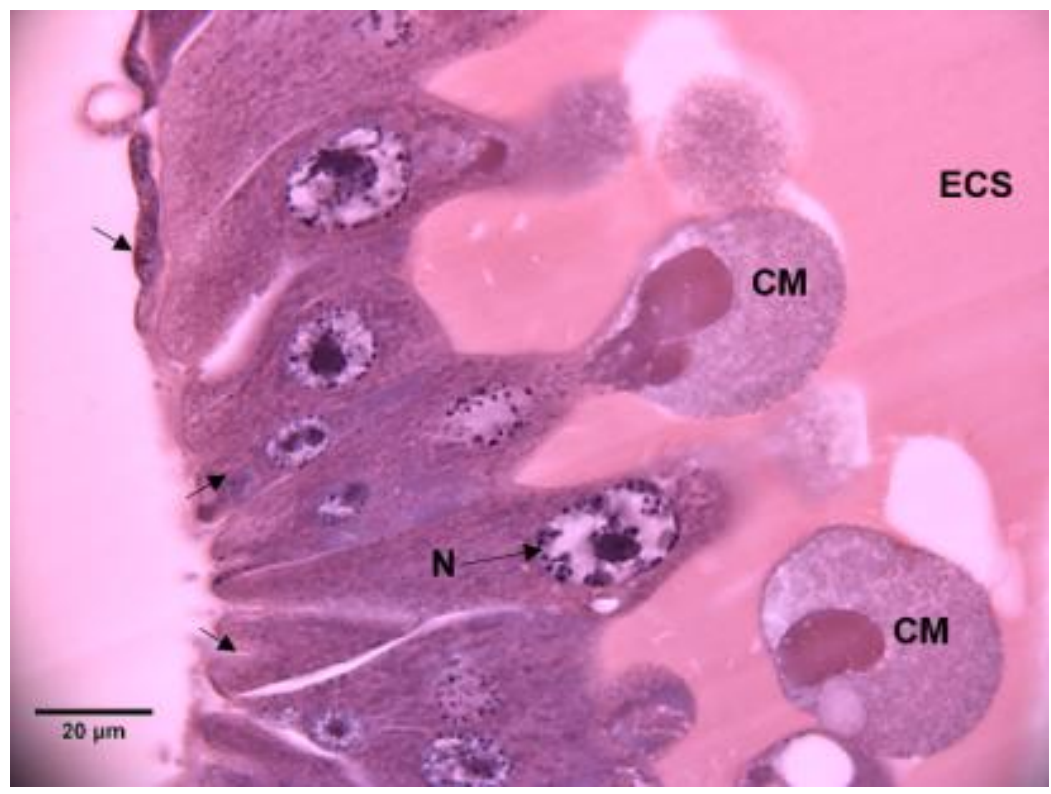

Fig. 8. Detailed view of epithelial cells with apocrine secretory activity, showing secretion into the lumen in the posterior region of the mesenteron. Stained with H\&E, image taken at $1000 \mathrm{X}$ magnification. CM, cellular material; ECS, ectoperitrophic space; N, nucleus. Arrows indicate regenerative cells 
According to [23] the epithelial cells do not undergo mitosis, with replacement and growth of tissue only occurring by embryonic cell differentiation. These cells are unable to differentiate into organs in adults, in contrast to those that grow from cell multiplication like the nervous system and fatty body.

Secretory activity and consequent cell anatomy is related to the digestive enzymes derived from epithelial cells because mosquitoes do not have specialized cells for such activities, which is different to other insects. No Goblet cells could be identified in the samples, confirming the description by [24] in studies evaluating the carbonic anhydrase in Ae. aegypti larval mesenteron. [25] also investigated the presence of this cell type, but they did not find any evidence of Goblet cells in mosquitoes.

The tangential sections showed that the epithelial tissue has a polygonal appearance. Observation of these sections can often cause confusion as the structure of the tissue may indicate cellular disorganization or stratification if complete evaluation of sequential sections is not performed (Figs. 9 and 10).

It is possible to verify a clear morphological change in the tissue closer to the hindgut. However, even in midgut samples presenting a well-defined pattern of epithelial tissue, the cells in segments $\mathrm{V}$ and $\mathrm{VI}$ show intense secretory activity, and consequently, do not seem to follow a particular morphological pattern.

The transition region between the mesenteron and proctodeum shows a contrast due to the abrupt change in epithelial tissue (Fig. 11). In this region we can identify the pyloric Chamber (or pylorus), the insertion of five Malpighian tubules and the beginning of the ileum, which moves food to the colon and finally to the anus.

The proctodeum presents a single layer of columnar and irregular cubic epithelial cells; however, this region is not easily visualized as the height of sections differs from other regions. According to [26], cellular attachment in this region occurs via septate desmosomes and gap junctions, which connect the edges of the cells and serve as a barrier against fluids and molecules that could pass between adjacent cells.

\subsection{Histochemical Aspects}

The histochemical characterization showed a positive reaction to acid lipids, total proteins, polysaccharides and blue/purple metachromasy, but was negative for red metachromasy and neutral lipids.

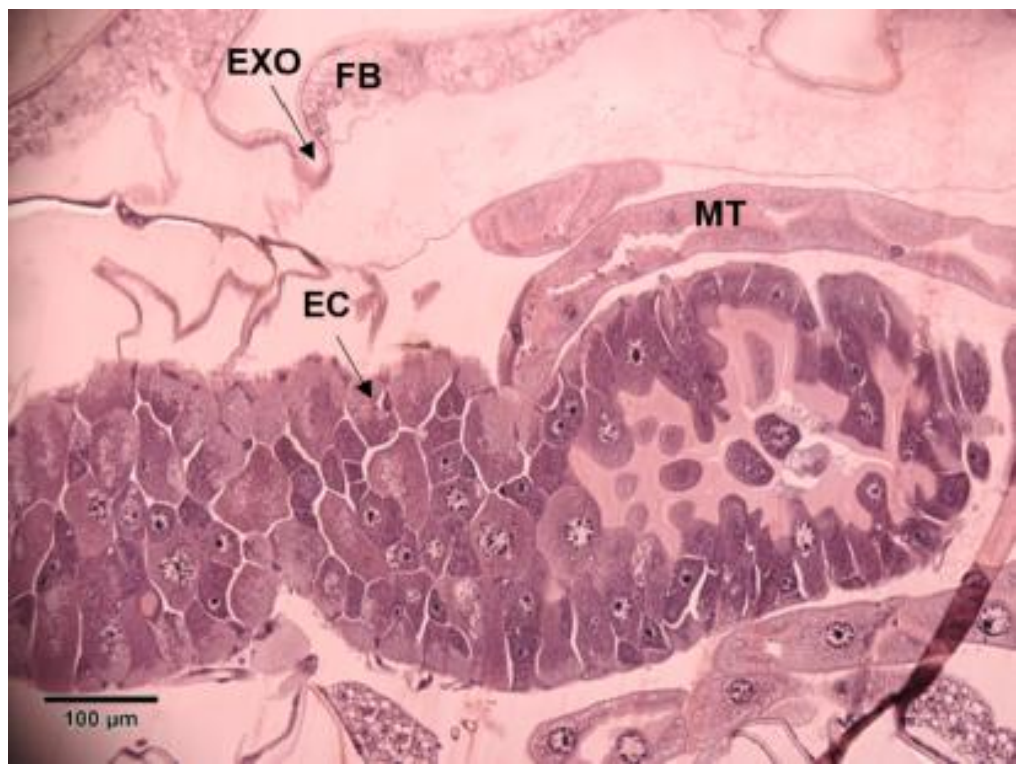

Fig. 9. Tangential section showing the general appearance of tissue in the transition between the middle and posterior regions of the mesenteron, as well as the insertion of Malpighian tubules. Stained with H\&E, image taken at 200X magnification. EC, epithelial cells; EXO, exoskeleton; FB, fat body; MT, Malpighian tubules 


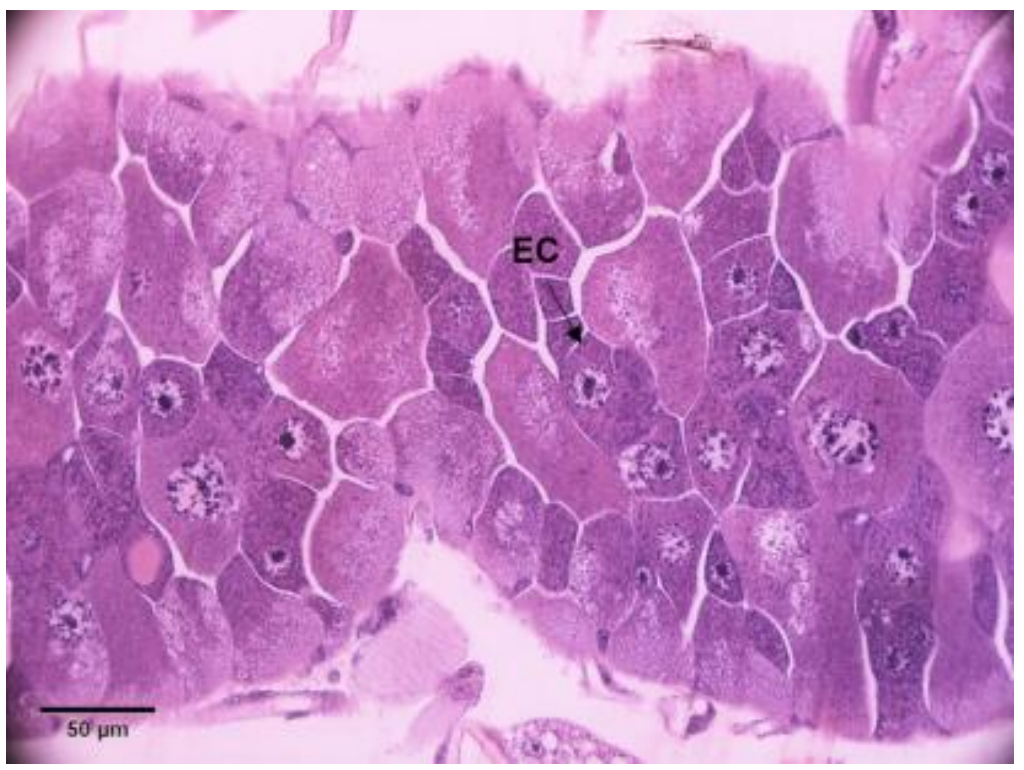

Fig. 10. Detailed view of the cells in a tangential section of tissue showing a polygonal appearance in the transition between the middle and posterior regions of the mesenteron. Stained with H\&E, image taken at $400 X$ magnification. EC, epithelial cells

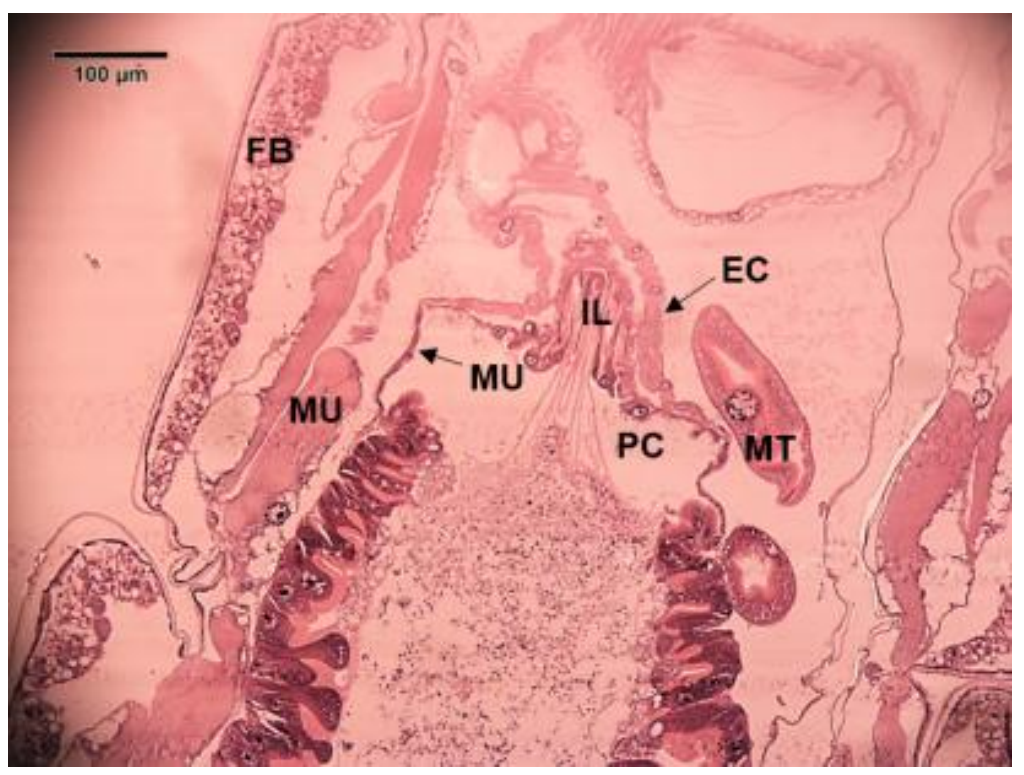

Fig. 11. Transition between mesenteron and proctodeum in which the epithelial tissue shows an abrupt morphological change. Stained with H\&E, image taken at 200X magnification. EC, epithelial cell; FB, fat body; IL, ileum; MT, Malpighian tubules; MU, muscle; PC, pyloric chamber or pylorus

The PAS reactions showed polysaccharidecontaining granules distributed throughout almost all tissues. The high concentration of these granules in the muscular tissues and fat body should be noted, as this results in darkened staining of the regions (Fig. 12). Epithelial cells that were in the process of secretion have a higher concentration of these granules in their apical zones (Fig. 13).

According to [23] the fat body is the main storage organ, containing lipid and protein globules 
inside the cytoplasm as well as glycogen vacuoles at the periphery of the cell. Muscle sarcoplasm is also a reservoir of glycogen, and glycogen can also be found in the gastric caeca, posterior midgut and nervous system cells
[23,27-28]. Thus, the granules highlighted by the PAS reaction may indicate the presence of glycogen, which is a polysaccharide energy reserve.

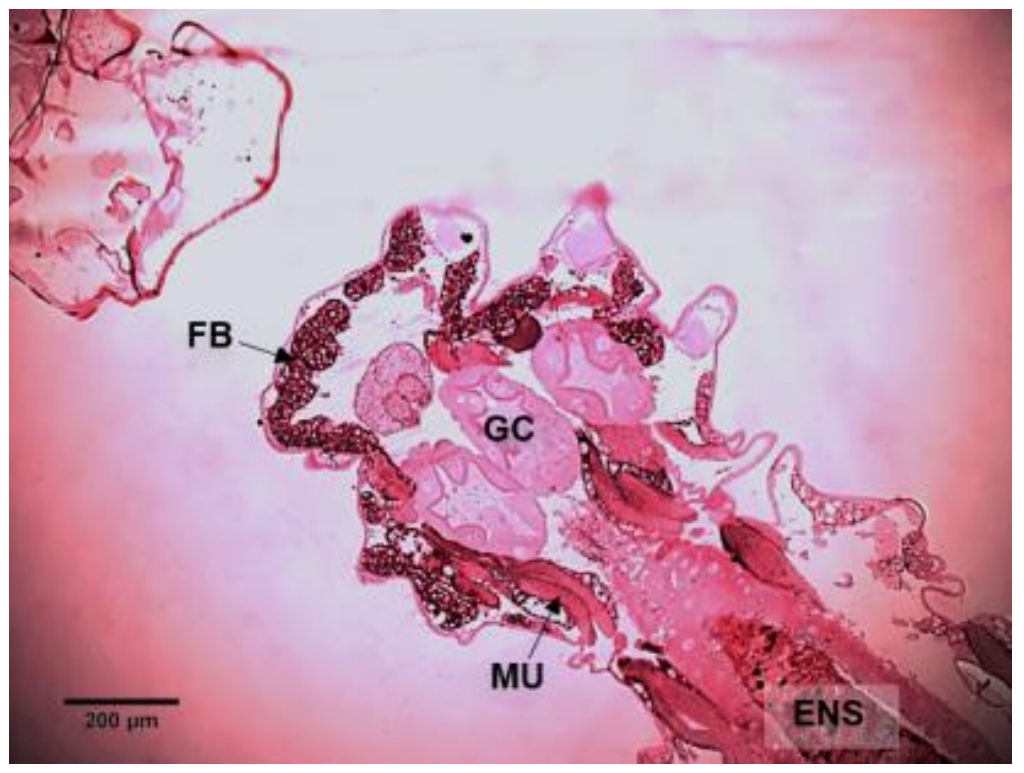

Fig. 12. Transition between mesenteron and proctodeum in which the epithelial tissue shows an abrupt morphological change. Stained with PAS, image taken at $100 \mathrm{X}$ magnification. ENS, endoperithophic space; FB, fat body; GC, gastric caeca; MU, muscle

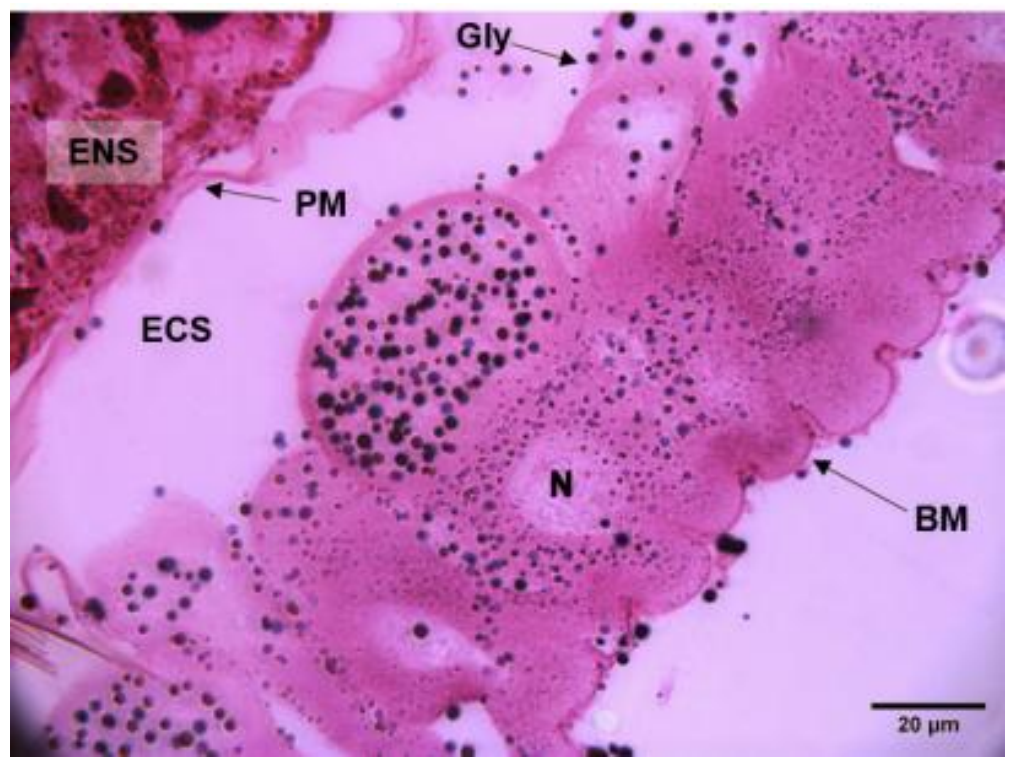

Fig. 13. Detail of middle midgut epithelial cells with well-defined polysaccharide granules. Stained with PAS, image taken at 1000X magnification. BM, basal membrane; ECS, ectoperitrophic space; ENS, endoperithophic space; Gly, glycogen; N, nucleus;

\section{PM, peritrophic membrane}


The proventriculus cells were stained by all applied histochemistry techniques, with Nile blue showing the weakest positive staining. As shown in Fig. 14, it is possible to compare the same structure with the various dyes. A stronger lipid reaction occurred in the alimentary material of the midgut when compared to the weak reaction in the cells. It is also possible to compare staining with the reaction of the fat body, the lipid storage organ. The membranes of the proventriculus could be visualized by bromophenol blue and PAS staining, which also showed glycogen reserves in the structure. Chitinous thickening was present at the base of the cells of the cardia, and Nile blue staining showed that there may be a higher lipid concentration in this region.

The peritrophic membrane along the midgut was evidenced only by PAS staining, probably due to its chitinous nature. [29] found that while this structure is composed of chitin, glycosaminoglycans and proteins, bromophenol blue only weakly indicated its presence. The intestinal epithelial cells evidenced by PAS staining contained many glycogen granules; however, there may be a switch between rich and poor cells of these.

The secretion showed a rich composition of proteins and polysaccharides, containing less lipids. The ectoperitrophic space presented a high free protein content, but it was not possible to determine if this originated from the epithelial or endoperitrophic space. The comparison between dyes for staining secretions is shown in Fig. 15.

The brush border and basement membrane were evident from the PAS reactions, while bromophenol blue only stained the microvilli. Nile blue did not indicate the lipid origin in these structures (Fig. 16).
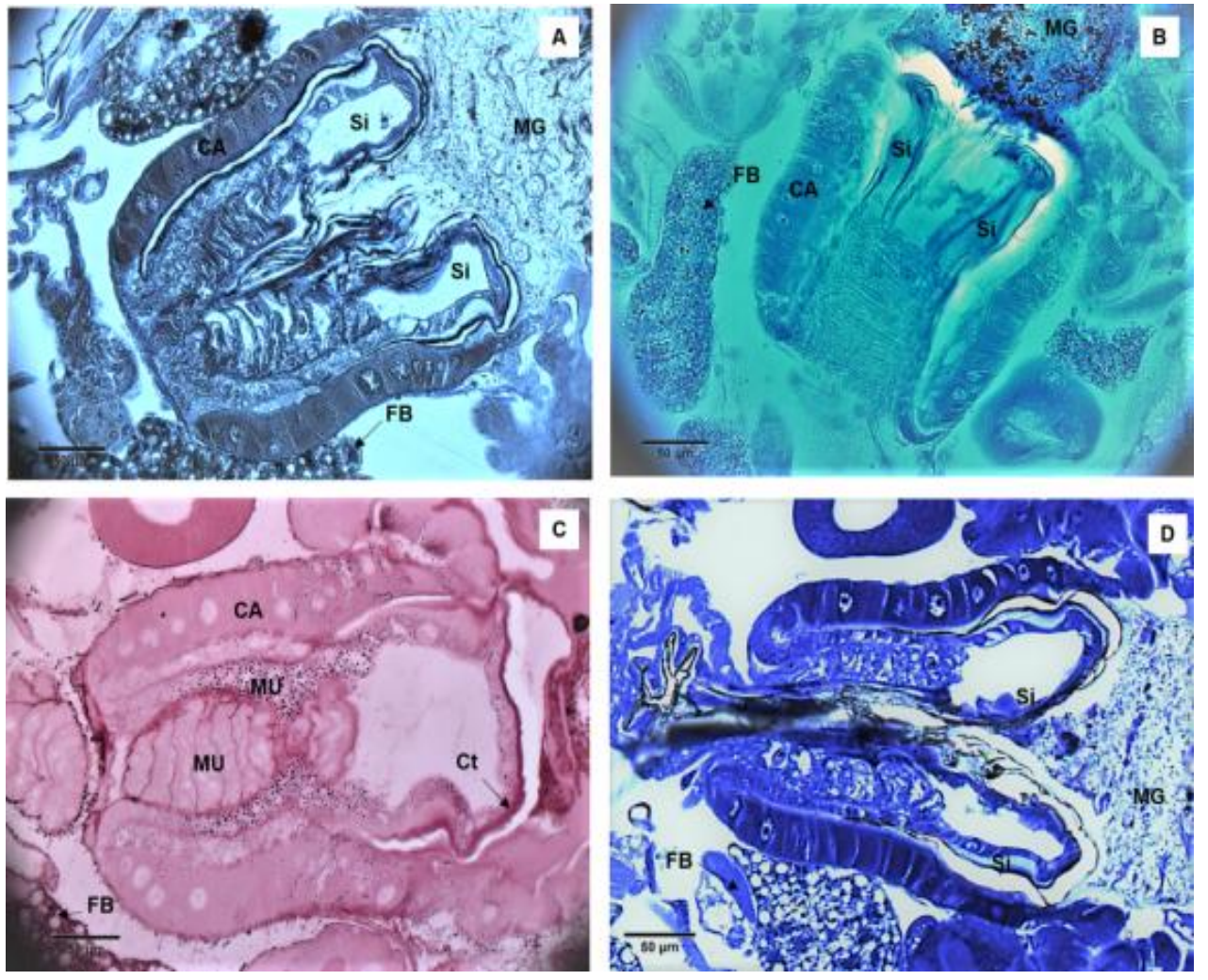

Fig. 14. Detail of proventriculus stained with (A) bromophenol blue, (B) Nile blue, (C) PAS and (D) toluidine blue. Image taken at $400 \mathrm{X}$ magnification. CA, cardia cells; $\mathrm{Ct}$, chitinous thickening; FB, fat body; MG, midgut; Si, sinus 

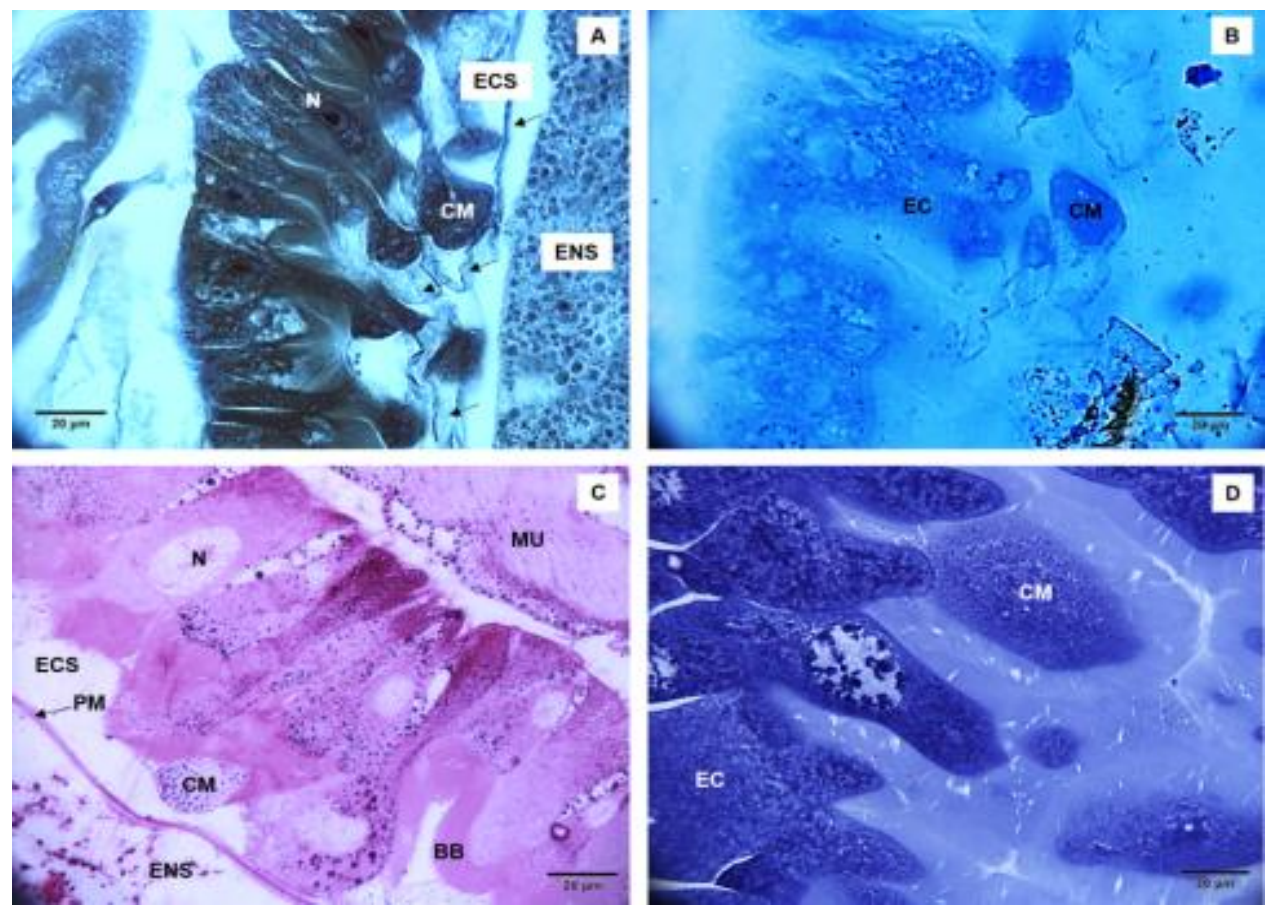

Fig. 15. Comparison between dyes for staining secretion or cellular material for $(A)$ bromophenol blue, (B) Nile blue, (C) PAS and (D) toluidine blue. Image taken at 1000X magnification. BB, brush border; CM, cellular material; EC, epithelial cell; ECS, ectoperitrophic space; ENS, endoperitrophic space; N, nucleus; MU, muscle; PM, peritrophic membrane. Arrows indicate protein-containing substance
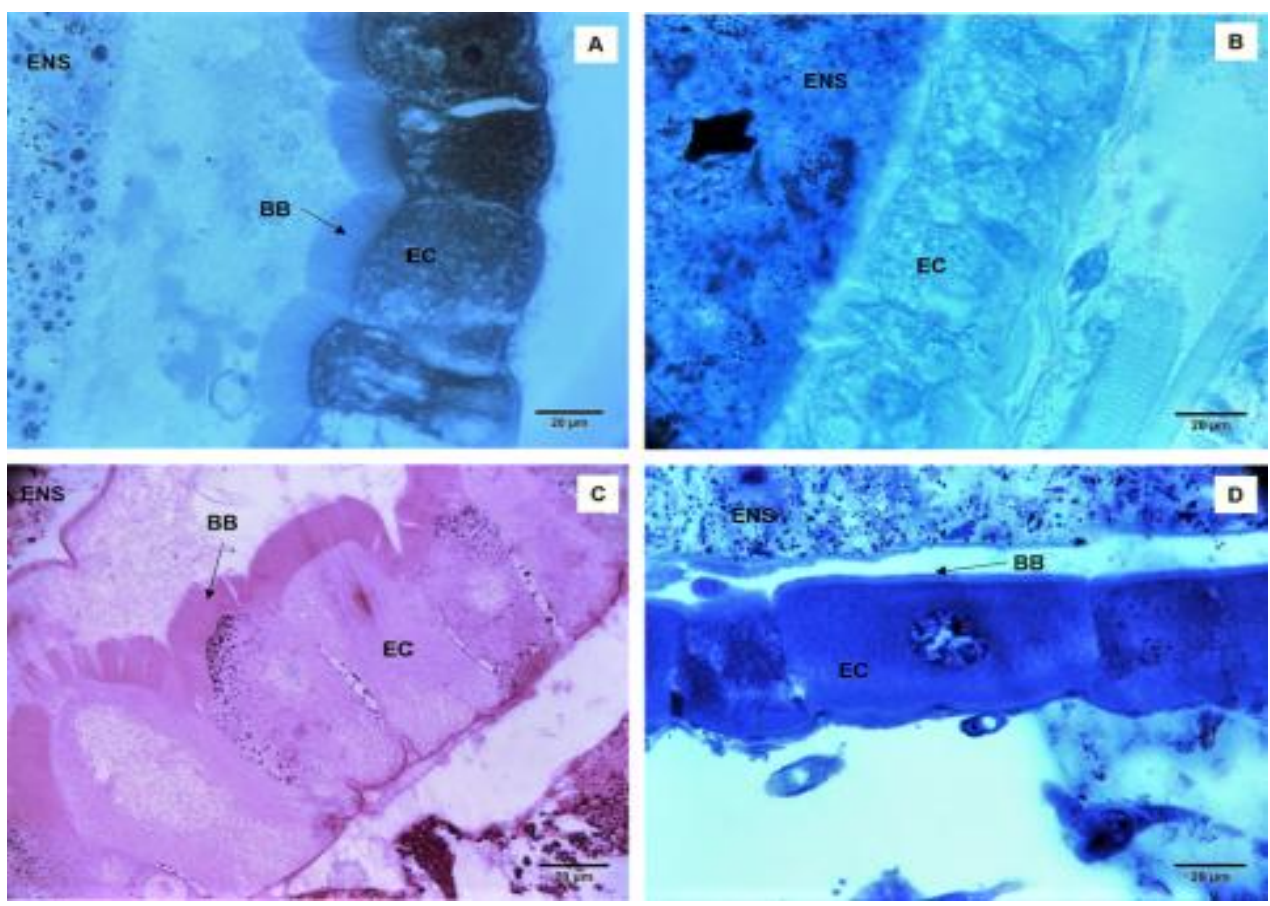

Fig. 16. Comparison between brush boarders stained with different dyes. (A) Bromophenol blue, (B) Nile blue, (C) PAS and (D) toluidine blue. Image taken at 1000X magnification 


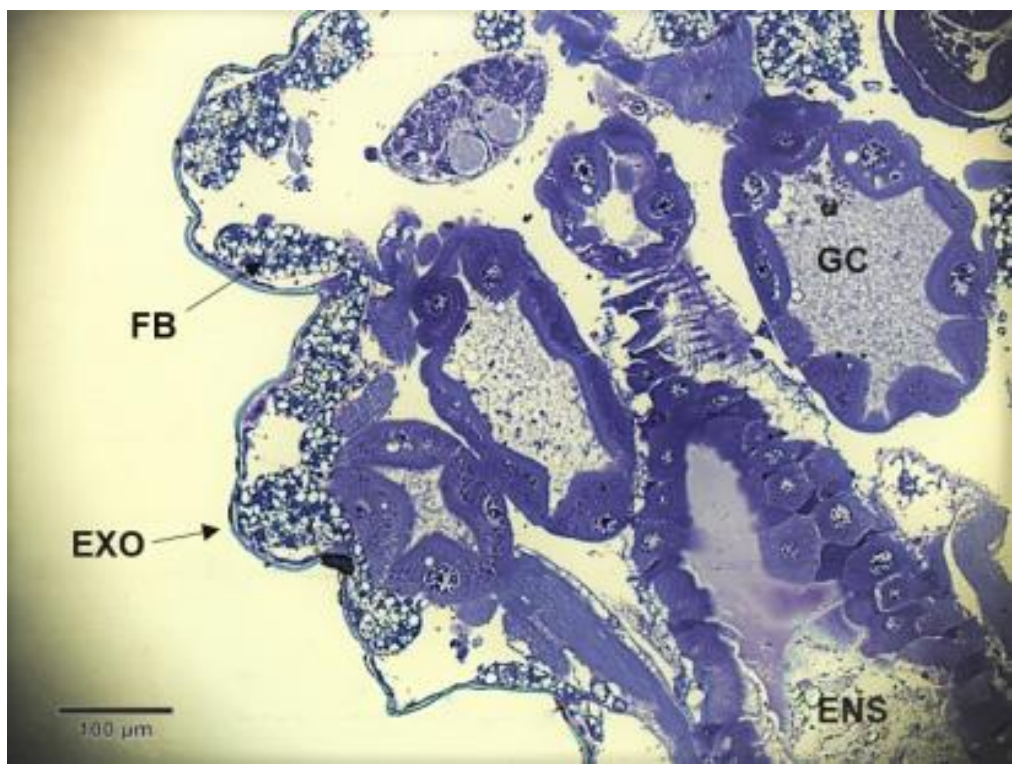

Fig. 17. The metachromasia showing the structures stained in purple or violet tones while the exoskeleton remained in light blue tones. Stained with toluidine blue dye, image taken at 200X magnification. ENS, endoperitrophic space; EXO, exoskeleton; FB, fat body; GC, gastric caeca

While the toluidine blue dye did not show red metachromasia in any structure, it did show color variation between the internal structures and the integument. The structures were stained in purple or violet tones, while the exoskeleton remained a light blue tone (Fig. 17). The tegument of the larva, or cuticle, is composed of some proteins and has a non-chitinous outer covering, called the epicuticula [30].

\section{CONCLUSION}

This study enabled a better understanding of cellular differences and basic histochemical features that occur throughout the intestinal tract of $A$ e. aegypti healthy larvae. In addition, the images presented collaborate to a better understanding and visualization of the healthy structures, allowing researchers to have a clearer assessment on the possible damage caused by exposure to chemical compounds, isolated products of plants, microorganisms, and others.

\section{COMPETING INTERESTS}

Authors have declared that no competing interests exist.

\section{REFERENCES}

1. Kraemer MUG, Sinka ME, Duda KA, Mylne AQN, Shearer FM, Barker CM, et al. The global distribution of the arbovirus vectors Aedes aegypti and Ae. albopictus. ELife 4 (e08347); 2015.

DOI: $10.7554 /$ eLife.08347

2. Carvalho FD, Moreira LA. Why is Aedes aegypti Linnaeus so Successful as a Species? Neotrop Entomol. 2017;46(3): 243-255.

DOI: $10.1007 / \mathrm{s} 13744-017-0520-4$

3. WHO - World Health Organization; 2017. (Accessed 15 November 2017)

Available:http://www.who.int/denguecontrol lepidemiology/en/

4. Bhatt S, Gething PW, Brady OJ, Messina JP, Farlow AW, Moyes CL, et al. The global distribution and burden of dengue. Nature. 2013;496(7446):504-7.

DOI: $10.1038 /$ nature12060

5. Corbel V, Fonseca DM, Weetman D, Pinto $J$, Achee NL, Chandre F, et al. International workshop on insecticide resistance in vectors of arboviruses, December 2016, Rio de Janeiro, Brazil. Parasit Vectors. 2017;10(1):278.

DOI: 10.1186/s13071-017-2224-3

Erratum in: Parasit Vectors. 2017;10 (1):3916.

DOI: 10.1186/s13071-017-2224-3

6. Després L, Stalinski R, Tetreau G, Paris M, Bonin A, Navratil V, et al. Gene expression patterns and sequence polymorphisms associated with mosquito resistance to 
Bacillus thuringiensis israelensis toxins. BMC Genomics. 2014;15:926.

DOI: 10.1186/1471-2164-15-926

7. Bonin $A$, Paris $M$, Frérot $H$, Bianco $E$, Tetreau G, Després L. The genetic architecture of a complex trait: Resistance to multiple toxins produced by Bacillus thuringiensis israelensis in the dengue and yellow fever vector, the mosquito Aedes aegypti. Infect Genet Evol. 2015;35:20413.

DOI: 10.1016/j.meegid.2015.07.034

8. Silva OS, Silva FC, Barros FMC, Silva JLR, Bordignon SAL, Eifler-Lima VL, et al. Larvicidal and growth-inhibiting activities of extract and benzopyrans from Hypericum polyanthemum (Guttiferae) against Aedes aegypti (Diptera: Culicidae). Industrial Crops and Products. 2013;45:236-39.

DOI:https://doi.org/10.1016/j.indcrop.2012. 12.025

9. Liu XC, Zhou L, Liu Q, Liu ZL. Laboratory evaluation of larvicidal activity of the essential oil of Allium tuberosum roots and its selected major constituent compounds against Aedes albopictus (Diptera: Culicidae). Journal of Medical Entomology. 2015;52(3):437-41.

DOI: $10.1093 /$ jme/tjv016

10. Silva OS, Prado GR, Silva JLR, Silva CE, Costa M, Heermann R. Oral toxicity of Photorhabdus luminescens and Xenorhabdus nematophila (Enterobacteriaceae) against Aedes aegypti (Diptera: Culicidae). Parasitology Research. 2013;112(8):2891-96.

11. Silva JLR, Schwalm FU, Silva EC, Costa M, Heermann R, Silva OS. Larvicidal and growth-Inhibitory acativity of entomogenic bacteria culture fluids against Aedes aegypti (Diptera: Culicidae). J Econ Entomol. 2017;110(2):378-385.

DOI: 10.1093/jee/tow224

12. Chang KS, Shin EH, Yoo DH, Ahn YJ. Enhanced toxicity of binary mixtures of Bacillus thuringiensis subsp. israelensis and three essential oil major constituents to wild Anopheles sinensis (Diptera: Culicidae) and Aedes albopictus (Diptera: Culicidae). J Med Entomol. 2014;51(4): 804-10.

DOI: 10.1603/ME13128

13. Klowden MJ. Physiological Systems in Insects. 3rd edition. Elsevier Academic Press: San Diego; 2013.

14. Bailey $\mathrm{CH}$, Gordon R. Histopathology of Aedes aegypti (Diptera: Culicidae) larvae parasitized by Reesimermis nielseni (Nematoda: Mermithidae). Journal of Invertebrate Pathology.1973;22(3):435-41. DOI: 10.1016/0022-2011(73)90174-2

15. Arruda W, Oliveira GMC, da Silva IG. Toxicidade do extrato etanólico de Magonia pubescens sobre larvas de Aedes aegypti. Revista da Sociedade Brasileira de Medicina Tropical. 2003;36(1):17-25. Portuguese.

DOI:http://dx.doi.org/10.1590/S003786822003000100004

16. Barreto CF, Cavasin GM, Silva HHG, da Silva IG. Estudo das alterações morfohistológicas em larvas de Aedes aegypti (DIPTERA, CULICIDAE) submetidas ao extrato bruto etanólico de Sapindus saponaria Lin (SAPINDACEAE). Revista de Patologia Tropical. 2006;35(1):37-57. Portuguese.

17. Abed RA, Cavasin GM, da Silva HHG, Geris R, da Silva IG. Alterações morfohistológicas em larvas de Aedes aegypti (Linnaeus, 1762) (Diptera, Culicidae) causadas pela atividade larvicida do óleo-resina da planta medicinal Copaifera reticulata Ducke (Leguminosae). Revista de Patologia Tropical. 2007;36(1):75-86. Portuguese DOI: https://doi.org/10.5216/rpt.v36i1.1819

18. Oliveira CD, Tadei WP, Abdalla FC. Occurrence of Apocrine Secretion in the Larval Gut Epithelial Cells of Aedes aegypti L., Anopheles albitarsis LynchArribálzaga and Culex quinquefasciatus Say (Diptera: Culicidae): A defense strategy against infection by Bacillus sphaericus Neide? Neotropical Entomology. 2009;38(5):624-31. DOI:http://dx.doi.org/10.1590/S1519566X2009000500010

19. Valotto CFB, Cavasin G, da Silva HHG, Geris R, da Silva IG. Alterações morfohistológicas em larvas de Aedes aegypti (Linnaeus, 1762) (Diptera, Culicidae) causadas pelo tanino catéquico isolado da planta do cerrado Magonia pubescens (Sapindaceae). Revista de Patologia Tropical. 2010;39(4):309-21. Portuguese. DOI:10.5216/rpt.v39i4.13066

20. Valotto CFB, da Silva HHG, Cavasin G, Geris R, Filho ER, da Silva IG. Alterações ultraestruturais em larvas de Aedes aegypti submetidas ao diterpeno labdano, isolado de Copaifera reticulata (Leguminosae), e à uma fração rica em taninos de Magonia pubescens 
(Sapindaceae). Rev Soc Bras Med Trop. 2011;44(2):194-200. Portuguese.

DOI:http://dx.doi.org/10.1590/S003786822011005000010

21. Christophers SR. Aedes aegypti: the yellow fever mosquito. Its life history, bionomics and structure. Cambridge University Press: London; 1960.

22. O'brian JF. Origin and Structural Function of the Basal Cells of the Larval Midgut in the Mosquito, Aedes aegypti Linnaeus. Journal of the New York Entomological Society. 1966;74(1):59-63.

23. Clements AN. The Physiology of Mosquitoes. Pergamon Press: London; 1963.

24. Corena MP, Seron TJ, Lehman HK, Ochrietor JD, Kohn A, Tu C, Linser PJ. Carbonic anhydrase in the midgut of larval Aedes aegypti: Cloning, localization and inhibition. The Journal of Experimental Biology. 2002;205:591-602.

25. Shahabuddin M, Pimenta PFP. Plasmodium gallinaceum preferentially invades vesicular ATPase-expressing cells in Aedes aegypti midgut. Proc. Natl. Acad. Sci USA. 1998;95:3385-89.

26. Nation JL. Insect physiology and biochemistry. $2^{\text {nd }}$ edition. CRC Press, Taylor \& Francis: Boca Raton; 2008.

27. Wigglesworth VB. The storage of protein, fat, glycogen and uric acid in the fat body and other tissues of mosquito larvae. Exp. Biol. 1942;19:56-77.

28. Wiatt GR. The Biochemistry of Sugars and Polysaccharides in Insects. Advances in Insect Physiology. 1967;4:287-360.

DOI:https://doi.org/10.1016/S00652806(08)60210-6

29. Edwards MJ, Jacobs-Lorena M. Permeability and disruption of the peritrophic matrix and caecal membrane from Aedes aegypti and Anopheles gambiae mosquito larvae. Journal of Insect Physiology. 2000;46(9):1313-20.

DOI: $10.1016 / S 0022-1910(00) 00053-6$

30. Chapman RF. The Insects: Structure and Function. Cambridge University Press: New York; 1998.

(c) 2018 Lemos et al.; This is an Open Access article distributed under the terms of the Creative Commons Attribution License (http://creativecommons.org/licenses/by/4.0), which permits unrestricted use, distribution, and reproduction in any medium, provided the original work is properly cited.

Peer-review history:

The peer review history for this paper can be accessed here: http://sciencedomain.org/review-history/22646 